\title{
Titanium Dioxide Sol-gel Schottky Diodes and Effect of Titanium Dioxide Nanoparticle
}

\author{
Mohammad Maniruzzaman*, Lindong Zhai* Seongcheol Mun* and Jaehwan Kim ${ }^{\dagger}$
}

\begin{abstract}
This paper reports the effect of Titanium dioxide $\left(\mathrm{TiO}_{2}\right)$ nanoparticles on a $\mathrm{TiO}_{2}$ sol-gel Schottky diode. $\mathrm{TiO}_{2}$ nanoparticles were blended with $\mathrm{TiO}_{2}$ sol-gel to fabricate the Schottky diode. $\mathrm{TiO}_{2}$ nanoparticles showed strong anatase and rutile X-ray diffraction peaks. However, the mixture of $\mathrm{TiO}_{2}$ sol-gel and $\mathrm{TiO}_{2}$ nanoparticles exhibited no anatase and rutile peaks. The forward current of the Schottky diode drastically increased as the concentration of $\mathrm{TiO}_{2}$ nanoparticles increased up to $10 \mathrm{wt}$. \% and decreased after that. The possible conduction mechanism is more likely space charge limited conduction.
\end{abstract}

Keywords: Schottky diode, Nanoparticle, Titanium dioxide, Sol-gel

\section{Introduction}

Recently metal oxides have attracted great attention due to their remarkable optical, physical, chemical, and electronic properties [1, 2]. Among the metal oxides, titanium oxide $\left(\mathrm{TiO}_{2}\right)$ has a wide range of advantageous properties, such as chemical stability, photocatalytic activity, photosensitivity, and electrical conductivity and is applicable to electronic devices, chemical sensors, photocatalysts, solar cells, and photoelectrochemical cells [3-6]. These properties strongly depend on crystallite size and shape of the $\mathrm{TiO}_{2} . \mathrm{TiO}_{2}$ has three main crystalline structures including anatase, rutile and brookite. Each structure has unique chemical, physical, and electronic properties and leads different applications.

$\mathrm{TiO}_{2}$ thin films have been fabricated with a variety of techniques including sol-gel process, sputtering with different metallic and ceramic targets, ion beam enhanced deposition, chemical vapor deposition, and pulsed laser deposition. Sol-gel process is one of the most important techniques to synthesize various functional materials. It has advantages over conventional other techniques in terms of low temperature process, large area coating, homogeneous and multi-component metal oxide preparation and low equipment cost. Although sol-gel process has such a superior advantages, the final material performance is greatly affected by the process conditions including species of solvent, concentration of $\mathrm{TiO}_{2}$ and heating process.

In this paper, we report the fabrication of a Schottky diode made by mixing $\mathrm{TiO}_{2}$ nanoparticles and $\mathrm{TiO}_{2}$ solgel. Schottky diodes have been made with inorganic

$\dagger$ Corresponding Author: Dept. of Mech. Eng., Inha University, Korea. (jaehwan@inha.ac.kr)

* Dept. of Mech. Eng., Inha University, Korea. (mamun08me@ yahoo.com,duicaofei@naver.com,bobtf@daum.net)

Received: January 15, 2015; Accepted: May 24, 2015 semiconducting material, conducting polymers and a combination of both materials [7-10]. The effect of $\mathrm{TiO}_{2}$ nanoparticles in the $\mathrm{TiO}_{2}$ sol-gel for the performance of Schottky diode is investigated in terms of surface field emission scanning electron microscope (FESEM) images, $\mathrm{X}$-ray diffraction (XRD) patterns and current-voltage (I-V) characteristics of the fabricated Schottky diode. Three possible conduction mechanisms are explained to determine dominant conduction process in the device.

\section{Experimental procedure}

$\mathrm{TiO}_{2}$ nanoparticles $(\sim 30 \mathrm{~nm})$ were purchased from Aldrich Co. and used without further purification. The $\mathrm{TiO}_{2}$ sol was fabricated by titanium (IV) isopropoxide (TIP, $97 \%)$, ethanol $(99.8 \%), \mathrm{HCl}(36.4 \%)$ and deionized (DI) water. The sol was prepared as follows: $50 \mathrm{ml}$ of ethanol was charged in the $100 \mathrm{ml}$ of round bottom flask, and $6 \mathrm{~g}$ of TIP was added to the solution. Then, $\mathrm{HCl}$ was added to the mixture until the solution became transparent with stirring, and the solution was kept under vigorous stirring for 1 day. The aqueous $\mathrm{TiO}_{2}$ nanoparticle solution was directly mixed with $\mathrm{TiO}_{2}$ sol-solution with $1 \mathrm{wt} \%$ (TiO-1), $5 \mathrm{wt} \%$ (TiO-5), $10 \mathrm{wt} \%$ (TiO-10), and $15 \mathrm{wt} \%$ (TiO-15) $\mathrm{TiO}_{2}$ nanoparticle concentrations. The various concentrations of $\mathrm{TiO}_{2}$ nanoparticles and $\mathrm{TiO}_{2}$ sol mixtures were spin coated on a silicon wafer with $2000 \mathrm{rpm}$. The film was then heated at $300^{\circ} \mathrm{C}$ for $1 \mathrm{~h}$ in a tube furnace under nitrogen gas purging. The silicon wafer was cleaned by a mixture of sulfuric acid and hydrogen peroxide in an ultrasonic cleaner, followed by cleaning and rinsing with de-ionized water. Finally, the wafer was washed with acetone and dried at $100^{\circ} \mathrm{C}$ for 30 minutes. The film thickness was approximately $100 \mathrm{~nm}$ after heat treatment. Al electrode was then vacuum-deposited onto the film. Fig. 1 shows the three-layered Schottky diode structure. 


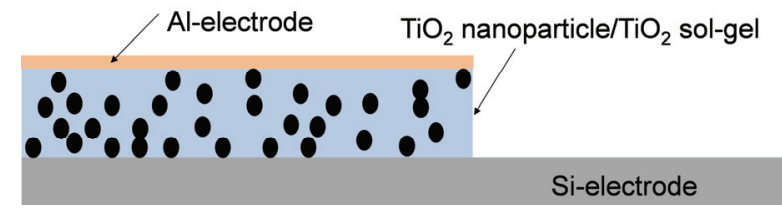

Fig. 1. Three-layered Schottky diode structure: $\mathrm{TiO}_{2}$ nanoparticle- $\mathrm{TiO}_{2}$ sol-gel acts as a semiconducting layer.

The silicon layer was used as an electrode.

\section{Results and Discussion}

Fig. 2 shows surface FESEM images of (a) TiO-1, (b) TiO-5, (c) TiO-10, and (d) TiO-15. Nanoparticles were not observed on the surface of the TiO-1 film. Small individual particles were observed for the TiO-5. As the concentration of $\mathrm{TiO}_{2}$ nanoparticles increased more than $10 \%$, aggregated particles were observed on the surface of the films as shown in Fig. 2 (d). Fig. 2(e) shows the cross sectional FESEM image of TiO-10. The thickness of the $\mathrm{TiO}_{2}$ layer is about $75 \mathrm{~nm}$.

Anatase and rutile crystallite phases are the main structures of $\mathrm{TiO}_{2}$, which have band-gap energies of 3.2 and $3.0 \mathrm{eV}$, respectively $[11,12]$. Anatase $\mathrm{TiO}_{2}$ has excellent photocatalytic activity, long-term stability and nontoxicity [13]. Sol-gel spin-coating process is a
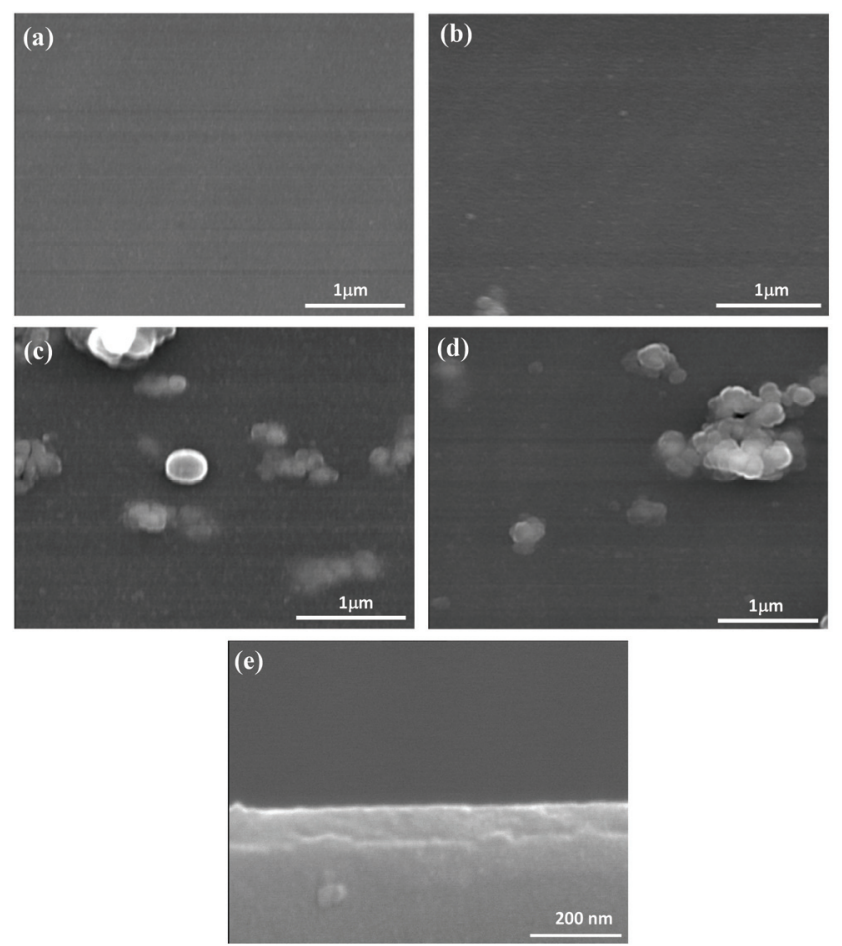

Fig. 2. FESEM surface images: (a) TiO-1; (b) TiO-5; (c) TiO-10; (d) TiO-15 and (e) FESEM cross-sectional image of TiO-10. promising technique over the other conventional techniques. The prepared films are mostly amorphous phase structures [14]. Fig. 3(a) shows the XRD patterns for the TiO-1, TiO-5, TiO-10 and TiO-15. There is no clear anatase or rutile diffraction peak for the TiO-1 and TiO-5. However, very weak major anatase (101) and rutile (110) diffraction peaks were observed for the TiO-10 and TiO-15. Fig. 3(b) shows XRD pattern for the $\mathrm{TiO}_{2}$ nanoparticles. Strong anatase (101) and rutile (110) peaks are located at $25.4^{\circ}$ and $27.5^{\circ}$ respectively. The relative intensities of the anatase and rutile diffraction peaks are 54.7 and $45.3 \%$, respectively. It is clear that the $\mathrm{TiO}_{2}$ nanoparticles are composed of anatase and rutile crystal structures.

Schottky diodes fabricated with mixture of $\mathrm{TiO}_{2}$ sol-gel and $\mathrm{TiO}_{2}$ nanoparticles with different concentrations were characterized by measuring their I-V characteristics. The work function of $\mathrm{Al}$ is low (approximately $4.1 \mathrm{eV}$ ) compared with $\mathrm{TiO}_{2}(5.1 \mathrm{eV}$ for anatase structure and 4.9 $\mathrm{eV}$ for rutile structure) [11]. Therefore, the $\mathrm{Al}$ and $\mathrm{TiO}_{2}$ nanoparticles and $\mathrm{TiO}_{2}$ sol contact might be a Schottky junction due to a big difference in the work functions. Furthermore, due to the similar work function of Si (4.52 eV) and $\mathrm{TiO}_{2}$, the $\mathrm{Si}$ and $\mathrm{TiO}_{2}$ nanoparticles and $\mathrm{TiO}_{2}$ sol junction could be an Ohmic contact. Fig. 4 shows the result. The forward bias current was approximately $30 \mu \mathrm{A}$ for the Schottky diode fabricated with pure $\mathrm{TiO}_{2}$ sol-gel without $\mathrm{TiO}_{2}$ nanoparticles. The forward current for the TiO- 1 is approximately $130 \mu \mathrm{A}$, which is 4 times higher than the pure sol-gel Schottky diode. As the amount of $\mathrm{TiO}_{2}$
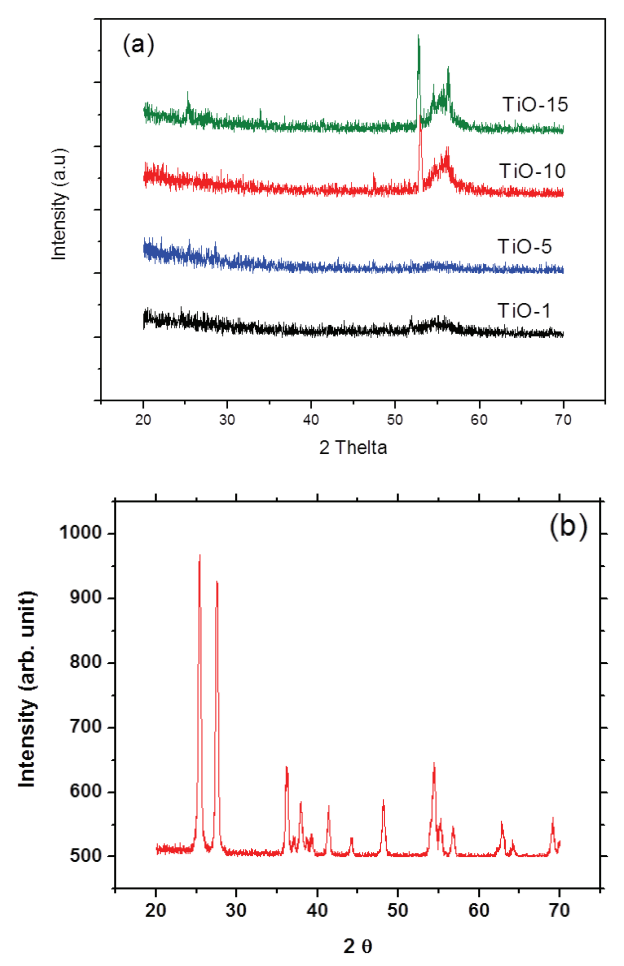

Fig. 3. XRD patterns: (a) TiO-1; TiO-5, TiO-10, and TiO15. (b) $\mathrm{TiO}_{2}$ nanoparticles. 


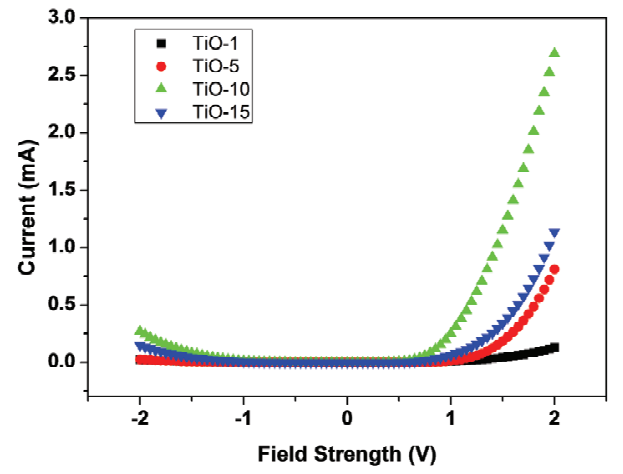

Fig. 4. I-V characteristics of Schottky diodes.

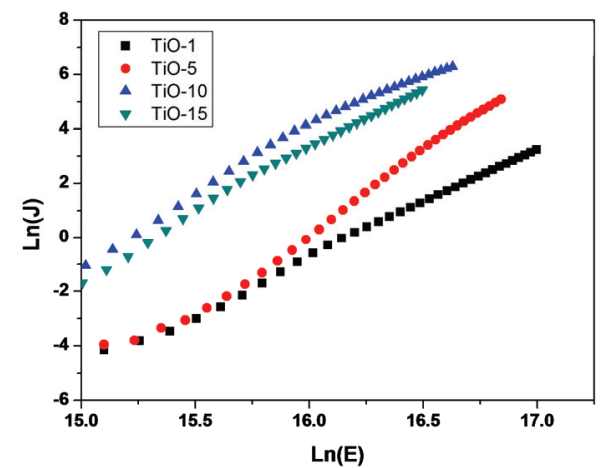

(a)

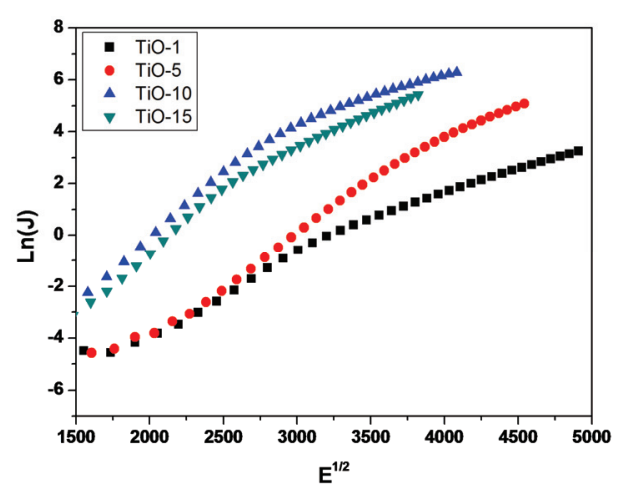

(b)

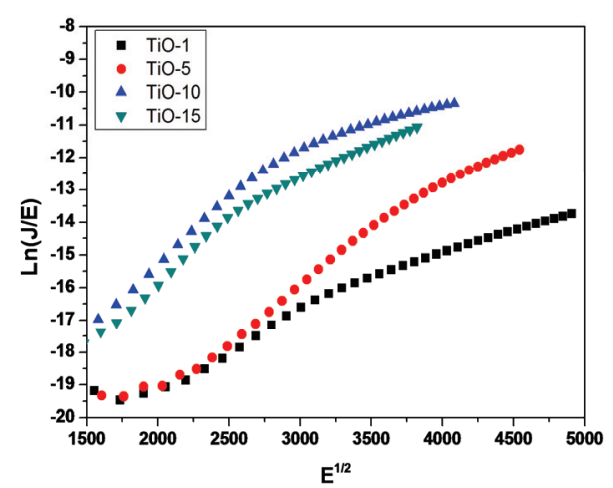

(c)

Fig. 5. The plots of three conduction mechanisms: (a) Ln $(J)$ vs $\operatorname{Ln}(V)$ for SCLC. (b) $\operatorname{Ln}(J)$ vs $E^{1 / 2}$ for $\mathrm{SC}$ and (c) $\operatorname{Ln}(J / V)$ vs $E^{1 / 2}$ for PFC.
Table 1. Beta values of $\mathrm{TiO}_{2}$ nanoparticle doped $\mathrm{TiO}_{2}$ solgel Schottky diodes of Schottky emission and Poole-Frenkel emission. Unit: $\times 10^{-5} \mathrm{eV} /(\mathrm{V} / \mathrm{m})^{1 / 2}$

\begin{tabular}{c|c|c}
\hline Samples & Schottky emission & Poole-Frenkel emission \\
\hline TiO-1 & 13.951 & 4.392 \\
\hline TiO-5 & 18.085 & 6.975 \\
\hline TiO-10 & 19.119 & 12.659 \\
\hline TiO-15 & 19.345 & 6.459 \\
\hline
\end{tabular}

nanoparticles increased, the forward current drastically increased up to $10 \mathrm{wt}$. $\%$ and decreased thereafter. The maximum forward current of $2.7 \mathrm{~mA}$ was achieved at 10 wt. $\%$ of $\mathrm{TiO}_{2}$ nanoparticles. The improved forward current is due to the high quality crystallite nanoparticles of $\mathrm{TiO}_{2}$, which drastically increase the surface area of the active material. The reduction of the forward current for the TiO-15 might be due to the aggregation of the $\mathrm{TiO}_{2}$ nanoparticles as shown in Fig. 2 (d).

To distinguish the major conduction mechanism, various plots were employed based on the theoretical equation of each conduction mechanism. Three conduction models were employed by plotting $\operatorname{Ln}(J)$ versus $\operatorname{Ln}(V), \operatorname{Ln}(J)$ versus $E^{1 / 2}$ and $\operatorname{Ln}(J / V)$ versus $E^{1 / 2}$ for the space charge limited conduction (SCLC), Schottky conduction (SC) and Poole-Frenkel conduction (PFC) models, respectively. Fig. 5 (a), (b) and (c) represent the plots based on the SCLC, SC and PFC models, respectively. Table 1 shows beta values of SC and PFC mechanisms in linear regime. For both cases, beta values are too big compared with the theoretical values $\left(3.03 \times 10^{-5} \mathrm{eV} /(\mathrm{V} / \mathrm{m})^{1 / 2}\right.$ for $\mathrm{SC}$ and $6.06 \times 10^{-5} \mathrm{eV} /(\mathrm{V} / \mathrm{m})^{1 / 2}$ for PFC) to match these mechanisms at low electric field [15]. The plot of SCLC model shown in Fig. 5(c) shows best linear fit in the experimental range. Therefore, SCLC process could be a major conduction mechanism [16].

\section{Conclusion}

The mixtures of $\mathrm{TiO}_{2}$ sol-gel and $\mathrm{TiO}_{2}$ nanoparticles with different concentrations of $\mathrm{TiO}_{2}$ nanoparticles were used as a semiconducting material for a Schottky diode fabrication. Although $\mathrm{TiO}_{2}$ nanoparticles show strong anatase and rutile XRD peaks, the mixtures of $\mathrm{TiO}_{2}$ sol-gel and $\mathrm{TiO}_{2}$ nanoparticles exhibit no characteristic anatase and rutile diffraction peak. The forward current drastically increased as the concentration of $\mathrm{TiO}_{2}$ nanoparticles increased until $10 \mathrm{wt} . \%$. The forward current decreased as the $\mathrm{TiO}_{2}$ concentration further increased. SCLC mechanism might be dominant for the linear regime.

\section{Acknowledgements}

This work was performed under the support of National Research Foundation of Korea (NRF-2013M3C1A3059586). 


\section{References}

[1] T.L. Chen, Y. Furubayashi, Y. Hirose, T. Hitosugi, T. Shimada and T. Hasegawa, "Anatase phase stability and doping concentration dependent refractivity in codoped transparent conducting $\mathrm{TiO}_{2}$ films," J. Phys. D: Appl. Phys., vol. 40, no. 19, pp. 5961-5964, Oct. 2007.

[2] O.V. Sakhno, L.M. Goldenberg, J. Stumpe and T.N. Smimova, "Surface modified $\mathrm{ZrO}_{2}$ and $\mathrm{TiO}_{2}$ nanoparticles embedded in organic photopolymers for highly effective and UV-stable volume holograms," Nanotechnol., vol.18, no.10, pp.105704, Mar. 2007.

[3] E.W. McFarland and J. Tang, "A photovoltaic device structure based on internal electron emission," Nature, vol. 421, pp. 616-618, Feb. 2003.

[4] H. Miyazaki, T. Hyodo, Y. Shimizu and M. Egashira, "Hydrogen-sensing properties of anodically oxidized $\mathrm{TiO}_{2}$ film sensors: Effects of preparation and pretreatment conditions," Sensor Actuat. B-Chem., vol. 108, pp. 467-472, July 2005.

[5] P. Yu, K. Zhu, A.G. Norman, S. Ferrere, A.J. Frank and A.J. Nozik, "Nanocrystalline $\mathrm{TiO}_{2}$ Solar Cells Sensitized with InAs Quantum Dots," J. Phys. Chem. $B$, vol. 110, no. 50, pp. 25451-25454, Nov. 2006.

[6] G. Wang, H. Chen, H. Zhang, Y. Shen, C. Yuan, Z. Lu, G. Wang and W. Yang, "Current-voltage characteristics of $\mathrm{TiO}_{2} /$ PPy complex films," Phys. Lett. A, vol. 237, no. 3, pp. 165-168, Jan. 1998.

[7] C. Chen, W. Zhang, B. Zhao and Y. Zhang, "Investigation of Schottky-Barrier carbon nanotube fieldeffect transistor by an efficient semi-classical numerical modeling," Phys. Lett. A, vol. 374, no. 2, pp. 309-312, Dec. 2009.

[8] S.Y. Yang, J. Kim and K.D. Song, "Flexible patch rectennas for wireless actuation of cellulose electroactive paper actuator," JEET, vol.7, no.6, pp.954-958, Nov. 2012.

[9] J. Nayak, S.K. Mahadeva, Y. Chen, K.S. Kang and J. Kim, "Effect of ionic liquid dispersion on performance of a conducting polymer based Schottky diode," Thin Solid Films, vol. 518, no. 19, pp. 56265628, July 2010.

[10] K.S. Kang, K.J. Han and J. Kim, "Polymer-Based Flexible Schottky Diode Made With PentacenePEDOT: PSS," Nanotechnol., IEEE Trans., vol. 8, no. 5, pp.627-630, Sep. 2009.

[11] A. Sclafani, L. Palmisano and M. Schiavello, "Influence of the preparation methods of titanium dioxide on the photocatalytic degradation of phenol in aqueous dispersion," J. Phys. Chem., vol.94, no.2, pp. 829-832, Jan. 1990.

[12] M.V. Rao, K. Rajeshwar, V.R. Pai Verneker and J. Dubow, "Photosynthetic production of hydrogen and hydrogen peroxide on semiconducting oxide grains in aqueous solutions," J. Phys. Chem., vol.84, no.15, pp.
1987-1991, July 1980.

[13] Z. Zhao and Q. Liu, "Mechanism of higher photocatalytic activity of anatase $\mathrm{TiO}_{2}$ doped with nitrogen under visible-light irradiation from density functional theory calculation," J. Phys. D: Appl. Phys., vol.41, no.2, pp.025105, Jan. 2008.

[14] H. Rath, P. Dash, T. Som, P.V. Satyam, U.P. Singh, P.K. Kulriya, D. Kanjilal, D.K. Avasthi and N.C. Mishra, "Structural evolution of $\mathrm{TiO}_{2}$ nanocrystalline thin films by thermal annealing and swift heavy ion irradiation,” J. Appl. Phys., vol.105, no.7, pp.074311, Apr. 2009.

[15] K.H. Yoo, K.S. Kang, Y. Chen, K.J. Han, J. Kim, "Direct and indirect contact effect between $\mathrm{Al}$ and $\mathrm{TiO}_{2}$ on the conduction mechanism for polymer- $\mathrm{TiO}_{2}$ Schottky diodes," J. Phys. D: Appl. Phys., vol.42, no. 7, pp. 075107, Feb. 2009.

[16] K.H. Yoo, K.S. Kang, Y. Chen, K.J. Han and J. Kim, "The effect of $\mathrm{TiO}_{2}$ nanoparticle concentration on conduction mechanism for $\mathrm{TiO}_{2}$-polymer diode," Appl. Phys. Lett., vol.93, no.19, pp.192113, Nov. 2008.

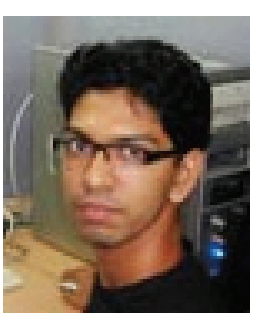

Mohammad Maniruzzaman $\mathrm{He}$ received B.S degree in Industrial \& Production Engineering in 2009 from Bangladesh University of Engineering and Technology, MS in Mechanical Engineering from Inha University 2011 And now he is $\mathrm{PhD}$ student in Institute for Frontier Materials in Deakin University. His research interests are cellulose, nanocomposite, biosensors, liquid plasma, plant biology and plasma medicine.

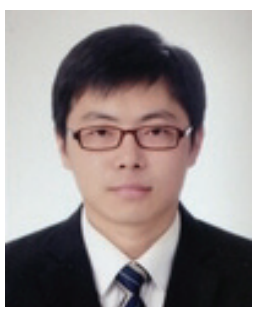

Lindong Zhai He received his B.E. in Automotive and Mechanical Engineering in 2011 from Howon University and M.S. in Mechanical Engineering in 2013 from Inha University. Now he is $\mathrm{PhD}$ student in Mechanical Engineering in Inha University. His research is focus on cellulose nanocrystal and

nanofiber.

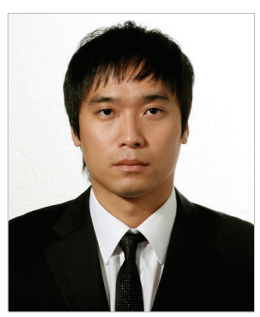

Seongcheol Mun He received his B.S. and M.S. degrees of Mechanical Engineering from Inha University in 2010 and 1012, respectively. $\mathrm{He}$ is now Ph.D. student in Mechanical Engineering, Inha University. His research interests are renewable smart materials and its device applications. 


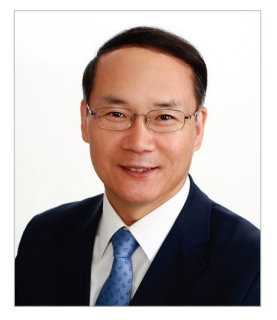

Jaehwan Kim Prof. Kim received his $\mathrm{Ph} . \mathrm{D}$. degree of Engineering Science and Mechanics from The Pennsylvania State University, USA, in 1995. Since then he joined Mechanical Engineering department of Inha University where he is now Inha Fellow Professor. Prof. Kim is a fellow of The National Academy of Engineering of Korea and The Korean Academy of Science and Technology. His research interests are smart materials such as piezoelectric materials, electro-active polymers, electro-active paper, and smart devices such as sensors, actuators, motors and MEMS. 